\title{
Research on the Status Quo and Existing Problems of Rural Energy Development in China
}

\author{
Wang Ning ${ }^{1, a}$, Li Zhao ${ }^{2, b^{*}}$ \\ ${ }^{1}$ Department of Economics in Xi'an Mingde Institute of Technology, Xi'an, Shaanxi, China \\ ${ }^{2}$ Department of Economics in Xi' an Mingde Institute of Technology, Xi'an, Shaanxi, China
}

\begin{abstract}
Over more than forty years of deepening reform and opening up, China has become the second largest world economy after the United States. As a component of energy system in China, rural energy is becoming more and more important. With the development of rural economy in China, the efforts of energy conservation and emission reduction have been continuously strengthened and expanded in China. Sustained, safe, and green energy supply is the material basis for the sustainable development of rural economy in China, and it is also a prerequisite for improving the quality of life of rural residents in China. Given living habits and income levels, energy consumption in rural areas in China is still dominated by traditional energy sources such as coal and firewood. There is little use and consumption of new energy. Rural energy is gradually declining for the investment in special funds for rural energy projects is not enough. New energy technology research and development are lagging. At the same time, rural areas have low using efficiency but high demand of energy, which leads more contradictions. In order to meet the needs of farmers for energy production and increase their income, it is necessary to study the countermeasures of rural energy development, which becomes an important part of the construction of a new socialist countryside. Based on the analysis of rural energy developing status and rural energy consumption structure in China, this article pointed out the problems including unreasonable energy structure, insufficient supply, the contradiction between supply and demand, and the lagging construction of follow-up service management system, and uncompleted energy support policies and imperfect incentive measures. We also put forward corresponding countermeasures and suggestions.
\end{abstract}

\section{Introduction}

In the wave of rapid development of the world economy, we are confronting tremendous pressure because of an ever-increasing population, limited resources and polluted environment. Reasonable development and utilization of energy are the foundation and motivation for maintaining steady and rapid economic development. However, rural areas are vast and populous in China. Rural energy construction is an important material basis for economic and social development. It is also an indispensable part of the national energy strategy. The main goal of developing modern agriculture and building a new socialist countryside also depends on the energy construction. For a long time, the per capita consumption of commercial energy in rural areas has been very low. The life in rural has mainly relied on traditional energy sources such as straw and firewood, which has caused serious damage to surface vegetation and reduced soil fertility. Meanwhile, direct combustion methods are used, resulting in low using efficiency and serious waste. This traditional and lowefficiency life mode has created a great burden on resources and the ecological environment. It severely restricted the economic development and ecological civilization construction in rural areas in China.
As a large agricultural country that is rising rapidly in the world, China has its agriculture occupying an important position in the national economy. The area and population of rural areas account for more than half of land area and population in China. The development of rural economy directly affects the overall economic development of our country. For development, China also advocates vigorously modern agriculture and revitalizes the rural economy. Therefore, we must solve the problem of rural energy development and build a new socialist countryside.

\section{Literature review}

With the rapid economic development, all countries have realized the importance of rural energy development. First, Laura Tolnov Clausen and David Rudolph (2020)1 pointed out that the energy transition was a good opportunity for rural economic development. Renewable energy applications occupy a large proportion in the future development of rural energy. It has great development potential. Luo et al. (2019)2 investigated the achievements of rural energy development, analyzed the rural energy consumption structure and the development of renewable energy, highlighted the main problems in rural energy

\footnotetext{
a604381626@qq.com

b*nwpulizhao@163.com
} 
development, and pointed out the imbalances in rural energy development. Zhang (2019)3 analyzed the favorable conditions, present problems and restrictive factors of the development of rural industrialization. He put forward countermeasures and suggestions for the development of rural renewable energy industry in China. Wang (2019) 4 believed that the development of clean energy in new rural areas should continue to work in terms of rural energy structure, level, situation and opportunities for clean energy.

\section{Current Status of Rural Energy Development in China}

\subsection{Analysis on the Status Quo of Rural Energy Consumption Structure}

Reform and opening up have been deepened. In China, rural economy has grown rapidly with the development of the national economy. Energy has become an important driving force for rural economic development. Rural energy consumption demand has expanded promptly, and energy consumption structure has gradually transformed into commercialization due to cost issues. However, at this stage, the rural energy and part of the energy consumption for production are still mainly fuelwood and coal. However, new energy and other clean energy account for

a relatively small proportion.

The economic development of central and western regions is subject to regional restrictions in China, and the rural energy consumption structure still uses crop stalks, trees and firewood as the main living energy. Due to the backward economic development of the region and the inconvenience of transportation, the cost of using coal and natural gas in rural areas is high, the energy consumption is burdened, and the consumption of clean energy is negligible. Although the living standards of farmers have gradually improved in recent years and the energy consumption structure has also been adjusted, the consumption of traditional energy such as coal in the economically backward rural areas is still low, and the consumption of clean energy accounts for less than $5 \%$ of the total energy consumption. The consumption structure is gradually showing that the consumption of natural gas and other clean energy is substituted for some traditional energy combustion, but the overall consumption structure has not been changed and optimized.

China has a vast territory, and the topographic features of different regions hinder the development of rural areas. At the same time, it also creates favorable conditions for the development of rural solar thermal resources, solar energy, mountain wind energy, geothermal energy, hydroelectric energy, and biomass energy. In 2017, the use of renewable energy in rural China accounted for $26.4 \%$ of the total rural energy consumption, of which household energy accounted for $68 \%$ of the total energy use.

Table 1 The main energy composition of rural areas in China in 2018

Unit: \%

\begin{tabular}{|c|c|c|c|c|c|}
\hline & nation & Eastern region & Central Region & Western Region & Northeastern region \\
\hline firewood & 44.2 & 27.4 & 40.1 & 58.6 & 84.5 \\
\hline coal & 23.9 & 29.4 & 16.3 & 24.8 & 27.4 \\
\hline Gas,natural gas & 49.3 & 69.5 & 58.2 & 24.5 & 20.3 \\
\hline methan & 0.7 & 0.3 & 0.7 & 1.2 & 0.1 \\
\hline electricity & 58.6 & 57.2 & 59.3 & 59.5 & 58.7 \\
\hline Solar energy & 0.2 & 0.2 & 0.3 & 0.3 & 0.1 \\
\hline Others & 0.5 & 0.2 & 0.2 & 1.3 & 0.1 \\
\hline
\end{tabular}

\subsection{The status quo of rural energy supply and demand}

The rural explicit energy resources and invisible energy resources have huge reserves, but they are unevenly distributed and scattered, making it difficult for large-scale development and utilization. From an overall perspective of our country, coal is widespread in North China and Northwest China, oil, natural gas and natural gas are distributed in the basins of Northwest China; hydropower resources are abundant in Southwest China; and petroleum and natural gas are distributed on the coastal continental shelf. The main energy group consumption areas are concentrated in the eastern coastal areas, and the distribution of resources and regional energy consumption are asymmetrical and the differences are obvious.

With the development of rural agriculture, people's demand for electricity, gasoline, diesel and various new energy sources has increased significantly. By 2017, In China rural energy consumption totaled 379 million tons of standard coal, of which rural production energy accounted for $32 \%$ and rural life energy accounted for $68 \%$. Per capita energy consumption in rural areas has been increasing. From 2000 to 2017, it increased at an average annual growth rate of $7 \%$; the energy consumption of rural residents increased at an average annual rate of $9.81 \%$. The increase in rural per capita consumption gives the credit to the decrease of the population base, the development of urbanization and the 
rural economy which were triggered by the transformation of the rural revitalization strategy. It has generally promoted the increase in the total rural energy demand.

From 2011 to 2018, taking electricity as an example, the country's rural electricity consumption increased from 713.96 billion $\mathrm{kWh}$ to 935.854 billion $\mathrm{kWh}$; the growth rate of rural electricity consumption was also increasing year by year, with the largest increase in 2013, reaching $16.1 \%$, and the increase has gradually slowed in recent years; rural per capita electricity consumption is also increasing year by year, from $1088 \mathrm{kWh}$ in 2011 to $1659 \mathrm{kWh}$ in 2018 . $\mathrm{kWh}$

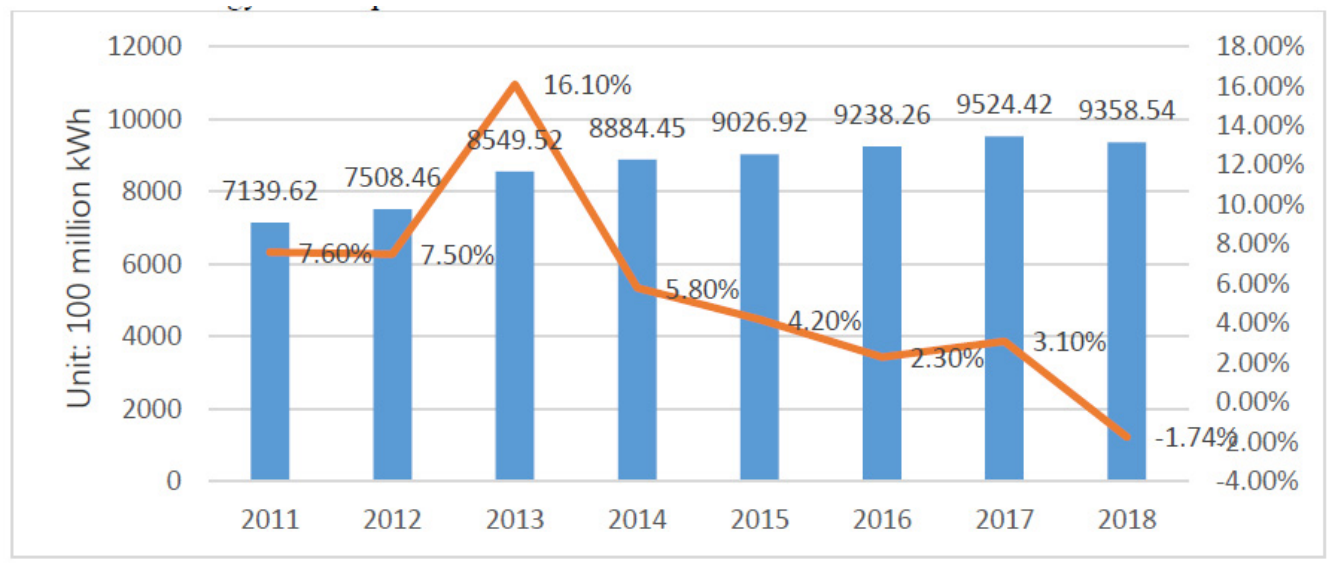

National Rural Electricitv Consumption

Rural electricity consumption growth rate

Figure 1 Changes in China rural electricity consumption from 2011 to 2018

\subsection{The status quo of the construction of rural energy service management system}

The rapid development of rural energy has driven the continuous growth of the rural renewable energy service industry, increased positive externalities, and has a more systematic and complete management service system. Government departments have established three-level rural energy management units at the provincial, township, and county levels to guide organizations, enterprises, and families to participate together, recruit talents, and realize the alignment of management cadres and technical talents. However, the construction of energy facilities still needs to be further strengthened. According to the third national agricultural census data, as of $2017,99.7 \%$ of the villages in the country had electricity, while only $11.9 \%$ of the villages had access to natural gas. Data shows that the construction of power grids in rural areas in China is steadily advancing, but it still has not reached $100 \%$ coverage; the coverage rate of natural gas in rural areas is only $11.9 \%$, indicating that the "coal-to-gas" project still needs to be carried out. This also reflects the imperfect construction of rural energy infrastructure in China.

Table 2 The penetration rate of rural energy facilities in China in 2017

\begin{tabular}{|c|c|c|c|c|c|}
\hline & \multicolumn{5}{|c|}{ Unit: \% } \\
\hline & nation & Eastern region & $\begin{array}{c}\text { Central } \\
\text { Region }\end{array}$ & Western Region & Northeastern region \\
\hline Electrified village & 99.7 & 100.0 & 99.9 & 99.2 & 100.0 \\
\hline Natural gas village & 11.9 & 10.3 & 8.4 & 18.3 & 4.7 \\
\hline
\end{tabular}

\section{Problems Existing in the Development of Rural Energy in China}

\subsection{Unreasonable rural energy consumption structure}

In China, the problem with rural energy utilization structure is that the main energy source in rural areas is still traditional energy sources such as coal and fuelwood, and the energy utilization rate is extremely low. In China, rural energy consumption structure differs greatly among regions and between the rich and the poor. The economic development of the western region is backward, energy demand is insufficient, and energy consumption is low. However, the energy consumption structure is based on the traditional primary energy such as coal and oil combined with emerging energy resources such as solar energy; the southeast region is the economic circle of China, which is economically developed, and the development of its rural areas has a strong radiation effect, and the supply and demand for energy is very large. However, its towns, villages and rural areas rely on traditional biomass energy such as firewood, which is seriously inconsistent with the degree of economic 
development, and has increased environmental pollution caused by rapid economic development. And ecological damage control costs; the economic belt along the Yangtze River is similar to the rural consumption structure in the southeastern region; the development of the central and eastern regions is more balanced than that of the western and southeastern regions.

The use of a large amount of raw coal and firewood destroys forest resources and surface ecology. It is difficult to refill in some mining areas, which makes it difficult to restore the ecology and causes large-scale surface subsidence. The problem of water and soil resource loss ensues, which further restricts the development of rural farmers and affects people's livelihood. The vicious circle of "energy-economy-people's livelihood-energy" is formed.

\subsection{Rural energy supply and demand imbalance}

According to data analysis, it can be clearly seen that the energy demand in rural areas has increased significantly in recent years in China, but the energy supply is insufficient. The overall characteristics of rural energy are abundant in total, but with low per capita, uneven distribution, and difficulty to develop in China. Most of the rural resources are distributed in the central, western and northern regions, but the southeast coastal area is the main energy consumption area of our country. Due to the limitation of transportation methods, energy extraction or production cannot be timely and accurately transported to the areas that need energy, in terms of time and space. A blank period of energy utilization has been formed. During this period, an imbalance of energy supply and demand will occur in areas that need energy.

Energy development is difficult. The geological mining conditions of coal resources in China are poor. Only a few of them can be mined in the open pit, and most of them need to be mined underground; oil and natural gas resources are deeply buried and require high exploration and development techniques; most of the undeveloped water resources are concentrated in the southwest mountainous area, making development difficult Big and high cost. Such a phenomenon cannot guarantee a stable supply of energy, but the demand for energy continues to increase steadily, which will cause an imbalance between energy supply and demand.

The technical level is low. In recent years, in China rural energy construction has made new breakthroughs, such as the use of solar water heaters, solar photovoltaic power technology and product utilization, and the development of wind energy. However, compared with developed countries, there is a certain gap in process technology, and production and investment costs are relatively high. The production scale is small and the competitiveness is not strong. In China, most of solar photovoltaic and other new energy projects are operated by private companies. Most of these companies have developed in recent years without a complete energy management system, insufficient capital investment, slow upgrading of equipment and technology, and energy utilization efficiency that cannot be improved rapidly.
Leading to more and more serious energy waste, which makes the rural energy supply in short supply more and more serious. At the same time, most of the rural areas did not make good use of the new energy equipment built due to many factors such as funds and the environment. Some areas are also caught in "energy shortage-deforestationecological destruction-energy shortage". In the vicious circle, rural development has been seriously affected.

\subsection{The construction of service management system is lagging behind}

At present, China has built more than 10,000 rural energy service sites and has professionals to guide energy development, but the distribution of rural energy service sites is unreasonable. Some rural areas have a small population but set up two or more energy service stations, while some areas with large populations have only one or no energy service station. This situation greatly reduces the value that existing energy service managers can play. Furthermore, the follow-up management work is not in place. In China, service management system construction is still advancing but lacks standardized measurement standards. At present, most of the high-quality professionals who have received training are professional and technical personnel, but there is only a small number of management cadre. In part, this led to the lack of a strict standard for subsequent energy construction and chaotic management, which greatly hindered the process of rural energy construction. At the same time, there are few township-level service stations, and professionals cannot promptly guide the correct use of new energy in rural areas, resulting in slower promotion of new energy technologies in rural areas.

\section{Countermeasures and Suggestions for In China Rural Energy Development}

\subsection{Adjust rural energy consumption structure}

Based on the above description, it can be found that there are big problems in China rural energy consumption structure, which seriously hinders the development of rural economy in China. It is necessary to rationally adjust the energy structure. By combining the actual situation in rural areas, adapting measures to local conditions and seeking truth from facts, we will formulate suitable energy development plans for different rural areas to reduce energy waste and environmental pollution. For example, Xinjiang and other regions with high solar radiation intensity can develop solar photovoltaic power generation projects; the north is rich in wind resources to develop small-scale wind power generation; the southern regions with abundant water resources and large terrain drop can develop small-scale hydropower generation.

By promoting new energy technologies through various channels, and regularly organizing learning and training for farmers to improve farmers' awareness of rural energy development and utilization is on the list so that farmers can accept and recognize the use of new energy in 
rural areas. Farmers can be proficient in new energy and renewable energy to reduce the use of traditional energy and high-polluting energy, thereby reducing environmental pollution, and providing a guarantee for the construction of a new socialist countryside with a beautiful environment.

\subsection{Strengthen the multi-energy complementary and comprehensive utilization of rural energy}

In order to effectively alleviate the shortage of energy in China rural areas, it is far from enough to rely solely on transportation from energy-rich areas. Technological innovation is also needed to improve rural energy use efficiency, achieve technological upgrades, reduce energy waste, and allow existing energy to play a better role.

It is necessary to coordinate the spatial and temporal differences and uneven distribution of rural energy use. Rural energy consumption should be deployed by winter and spring energy remaining for summer and autumn to realize the maximum meet of the energy needs in different seasons. All-round, multi-level real-time energy utilization of technology can develop long-term rural energy schemes. A comprehensive energy makes up for a lack of secondary energy, form the new rural energy development and utilization of systematic comprehensive model. Our goal is to improve the supply chain of rural energy, to extend the industrial chain of agricultural products, to carry out deep processing, fine processing, improving farmers' economic income, to broaden and to enrich the source of funds for the development of rural energy projects.

\subsection{Strengthen the construction of rural energy service system, and pay equal attention to construction and management}

To establish and improve the rural energy service management system with a wide coverage is a necessary condition for the rural energy construction project to give full play to its benefits. There are some problems in the rural energy service management system in China, such as unreasonable station distribution and chaotic supervision. Thus we have to put forward corresponding proposals to statistics in various rural areas of the actual needs of professional and technical personnel and energy infrastructure construction situation, according to the actual situation to adjust rural energy services site distribution, to give full play to the value of professional and technical personnel, promote energy infrastructure construction progress, for subsequent material foundation for the development of rural energy.

We aim to 1) increase funding and personnel input for the construction, operation and maintenance of rural clean energy facilities, and service systems to match energy construction tasks with the number of certified technicians, 2) increase the utilization rate of completed projects, 3) reduce the waste rate, and 4) increase village-level service outlets and personnel. Our goal is improving the assessment standards of the rural energy service management system, establishing a sound management system, realizing the professional access system, ensuring that the staff have real materials, having the ability of skillfully guiding farmers to master new energy use skills, and implementing legalization and institutionalization Management. Large-scale rural energy projects must be implemented by project legal person system, bidding system, project construction supervision system and project quality lifelong responsibility system.

\section{Conclusion}

The rural energy issue is not a simple economic or social issue, but a comprehensive issue involving politics, economics, culture, society, and scientific and technological development. Therefore, in order to better develop rural energy, we must consider all aspects and make a comprehensive analysis. This paper conducted indepth research on the current situation of rural energy development through a series of search literature and data analysis, finding that there are such problems as an irrational rural energy structure, insufficient rural energy supply, prominent contradictions between supply and demand, lagging behind the construction of a follow-up service management system, and rural energy support policies and policies. There are such fluencing factors as unsound incentive measures. Based on actual problems, this paper proposed to adjust measures to local conditions, upgrade the rural energy consumption structure, strengthen the complementary and comprehensive utilization of rural energy diversification, improve the construction of rural energy service system, pay equal attention to construction and management, increase policy support and capital investment.

\section{Reference:}

1. Laura Tolnov Clausen,David Rudolph. Renewable energy for sustainable rural development: Synergies and mismatches[J]. Energy Policy,2020,138.

2. Guoliang Luo, Jiaxin Zhang, Xiaopeng Guo, et al. In China rural energy development status and future prospects[J]. China Energy, 2019,41(2):37-43,24. DOI:10.3969 /j.issn. 1003-2355.2019. 02.008.

3. Songxin Zhang. Industrialization of Renewable Energy in Rural China: Current Situation, Cases and Countermeasures[J]. Journal of Anhui Agricultural Sciences, 2019,47(18):256-258,261. DOI:10.3969 /j.issn. 0517-6611.2019.18.071.

4. Yidong Wang. Development status and practical application analysis of clean energy in rural China $[\mathrm{J}]$. Contemporary Chemical Research, 2019 (7):2-4. DOI:10.3969/j.issn. 1672-8114.2019.07.002.

5. Pengfei Ma, Haimin Miao, Junfeng Zhu. Research on the Economic Effects of In China Rural Renewable Energy Policies[J]. Ecological Economy, 2020, 36(01):120-125. 